Luciane Pires de CAMARGO ${ }^{1}$

Lissandro Gonçalves

CONCEIÇÃO' ${ }^{1}$

Paulo Renato dos Santos

COSTA $^{1}$

\section{Correspondência para:}

Luciane Pires de Camargo

Endereço: R. Palmyra Moreira, 65 casa 2

Jardim Altos de Sant'Anna - Jacareí- SP

CEP. 1406-738

e-mail: luciane.camargo@gmail.com

Recebido para publicação em 11/07/2006 Aprovado para publicação em 20/03/2008

\title{
Neoplasias melanocíticas cutâneas em cães: estudo retrospectivo de 68 casos (1996-2004)
}

\author{
1 - Universidade Federal de Viçosa, Viçosa-MG
}

\section{Resumo}

Foram analisados 39 casos (42 lesões) de melanocitoma e 19 casos (19 lesões) de melanoma cutâneos caninos. Os melanocitomas acometeram tanto animais jovens como idosos, sem predisposição sexual. Neste estudo, os cães mais acometidos foram os da raça Schnauzer e Doberman, seguidos por aqueles sem raça definida. A maioria das lesões apresentou-se solitária e localizada na região palpebral, interdigital e torácica. Geralmente, as lesões eram papulares, alopécicas, não aderidas, enegrecidas, com consistência firme e diâmetro médio de 1,2 $\mathrm{cm}$. Recidivas e metástases não foram observadas, confirmando o bom prognóstico associado aos melanocitomas. Os melanomas acometeram animais mais idosos, sem predisposição sexual. Os cães mais acometidos foram os sem raça definida, seguida por aqueles das raças Rottweiler, Pinscher, Cocker Spaniel e Airedale. As lesões apresentaram-se solitárias e localizadas freqüentemente no lábio e na pálpebra. A maioria dos tumores apresentou-se ulcerado, nodular, com consistência firme e diâmetro médio de $2,5 \mathrm{~cm}$. Algumas lesões apresentaram recidivas. Metástases não puderam ser comprovadas. Dos casos com seguimento clínico conhecido, alguns foram curados pelo procedimento cirúrgico, entretanto, a maioria evoluiu para óbito, confirmando o prognóstico ruim associado ao melanoma.

\section{Introdução}

Os tumores melanocíticos originamse dos melanócitos e melanoblastos ${ }^{1,2}$ e ocorrem em todos os animais domésticos e de laboratório ${ }^{3}$. Os melanócitos são células dendríticas derivadas dos melanoblastos neuroectodérmicos que migraram para a epiderme, derme, membranas mucosas e coróide durante a embriogênese. Na pele, eles são encontrados na camada basal da epiderme, dispersos entre os ceratinócitos basais. Geralmente, os melanócitos não formam conexão ou contato entre si, mas junções aderentes e regulatórias com cinco a oito ceratinócitos vizinhos, por meio da molécula de adesão E-caderina. ${ }^{4}$ A melanina é produzida no melanócito, acondicionada nos melanossomos e transferida dos processos dendríticos aos ceratinócitos, pelo processo denominado citocrinia. ${ }^{5}$ Os melanossomos acumulados dentro do citoplasma dos ceratinócitos, servem para proteger a pele contra os efeitos prejudiciais da radiação ultravioleta. Os melanoblastos que falham em atingir a epiderme podem se desenvolver em melanócitos intradérmicos. Na derme, a segunda população de células que contêm melanina é a de melanófagos. Estas células fagocitam melanina que entra na derme após a morte de melanócitos foliculares ou epidérmicos. ${ }^{5}$ A conversão de melanócitos normais em neoplásicos é um processo constituído por múltiplas etapas, tendo a iniciação como evento primário, seguida por promoção, transformação e metástase. ${ }^{4}$

A terminologia das neoplasias melanocíticas nos animais domésticos não é homogênea. Alguns autores usam o termo melanoma cutâneo para descrever o tumor que demonstra diferenciação melanocítica, com potencial metastático não conhecido ou comprovado. ${ }^{6,7}$ Todavia, esses mesmos 
tumores têm sido chamados de melanocitoma por outros autores. ${ }^{4,8,9}$ Esse foi o termo escolhido pelos autores do presente estudo. Similarmente, autores usam o termo melanoma maligno para indicar o tumor que tem potencial metastático conhecido ou comprovado. ${ }^{6,7}$ Porém, o termo melanoma tem sido utilizado para esses tumores potencialmente malignos ${ }^{4,8,9} \mathrm{e}$ é o termo usado pelos autores deste trabalho.

$\mathrm{Na}$ medicina humana, as neoplasias melanocíticas foram identificadas na antiguidade e têm sido encontradas em indivíduos mumificados que viveram há mais de 2000 anos. O primeiro relato desses tumores na medicina veterinária foi realizado por Bunker em 1882, em um cão. ${ }^{1}$

Os humanos podem apresentar variadas lesões melanocíticas benignas e malignas ${ }^{10}$, e há correlação entre a exposição à radiação ultravioleta e o desenvolvimento do melanoma ${ }^{11}$. A expectativa é de que a forma cutânea do melanoma atinja um entre 75 indivíduos nascidos no ano de $2000 .{ }^{4}$ Nos cães, a predileção por algumas raças sugere que as neoplasias melanocíticas possam ter predisposição genética. Foram identificadas alterações na expressão ou função dos genes, tais como mutações ou expressões indetectáveis do $p 53, \mathrm{RB}-1$, CDKI, waf-1 e, ink-4 e suas respectivas proteínas envolvidas no controle do ciclo celular e apoptose, que podem ser de grande importância no desenvolvimento do melanoma. ${ }^{2}$

Nos cavalos tordilhos, o melanoma é muito comum. ${ }^{4} \mathrm{Na}$ espécie felina, as neoplasias melanocíticas benignas e malignas são incomuns e ocorrem praticamente com a mesma freqüência. ${ }^{9}$ Nos cães, as neoplasias melanocíticas são relativamente comuns 2,9,12,13, compreendendo 4 a 20\% de todas as neoplasias cutâneas dessa espécie, sendo que menos de $5 \%$ são malignas ${ }^{4}$. $\mathrm{Na}$ espécie canina, o melanoma é o tumor maligno mais comum da cavidade oral $2,4,14$ e dos olhos ${ }^{15}$, e a segunda neoplasia mais freqüente dos dígitos com localização subungueal ${ }^{4,}$. . Apesar de tal freqüência, ainda existem poucos estudos brasileiros que caracterizem do ponto de vista clínico, epidemiológico e anatomopatológico as neoplasias melanocíticas caninas. $O$ presente trabalho, a partir de um estudo retrospectivo sobre 58 casos de tumores melanocíticos cutâneos em cães no período de 1996 a 2004, descreve as características clínicas, epidemiológicas e microscópicas desses tumores diagnosticados no Setor de Dermatopatologia do Instituto de Diagnóstico PROVET de São PauloMoema e do Setor de Histopatologia Veterinária do Departamento de Veterinária da Universidade Federal de Viçosa (MG).

\section{Material e Método}

As lâminas histológicas para estudo sob microscopia ótica de luz foram obtidas junto ao arquivo do Setor de Dermatopatologia do Instituto de Diagnóstico PROVET de São PauloMoema e do Setor de Histopatologia Veterinária do Departamento de Veterinária da Universidade Federal de Viçosa (MG) no período de 1996 a 2004. Todas as lâminas histológicas estudadas foram confeccionadas a partir de espécimes cutâneos obtidos por médicos veterinários através de biópsia incisional ou excisional. Esses espécimes foram fixados em formalina $10 \%$, enviados ao laboratório, processados de maneira habitual e incluídos em parafina. As secções histológicas dos blocos de parafina foram realizadas com espessura entre 4 e $6 \mathrm{~mm}$ e coradas pela hematoxilina e eosina (HE). Uma lâmina com um caso de melanoma foi corada pelo método Fontana Masson com a finalidade de se confirmar a presença dos grânulos de melanina e outra com um caso de melanocitoma foi despigmentada e corada em HE, devido grande quantidade de pigmentação melânica que obscurecia a morfologia nuclear.

Foram selecionadas biópsias de 56 animais: dois apresentaram uma lesão melanocítica benigna e outra maligna em diferentes regiões do corpo. Portanto, foram analisados 58 casos de neoplasia melanocítica, 19 malignos e 39 benignos. Os critérios histológicos adotados para a 
diferenciação das neoplasias benignas e malignas estão de acordo com a literatura clássica. ${ }^{5,7,8,9,14,16}$ As lesões classificadas como melanocitoma apresentaram pleomorfismo celular e/ou nuclear ausente ou discreto e menos de três figuras mitóticas por dez campos de grande aumento (CGA) (40x) (Figura 1). Foram classificadas como melanoma, as lesões que apresentaram pleomorfismo celular e/ou nuclear de discreto a intenso e mais de duas figuras mitóticas por dez CGA (40X) (Figura 2), entre outras alterações, como hipercromasia, núcleos vesiculares, nucléolos conspícuos e mitoses atípicas. Dois casos de melanoma amelanótico foram submetidos à técnica de imunoistoquímica, com os imunomarcadores S-100, vimentina, citoqueratina e HMB-45, sendo o diagnóstico confirmado com a presença de imuno-reatividade às proteínas S-100 e vimentina e com a ausência de marcação pela citoqueratina.

Os médicos veterinários responsáveis pelos casos selecionados foram questionados, através de contato telefônico, para a obtenção das seguintes informações: identificação do animal (idade, sexo e raça); características macroscópicas das lesões (número, localização, cor, consistência, alopecia, tamanho, ulceração, forma e
$1 \mathrm{a}$

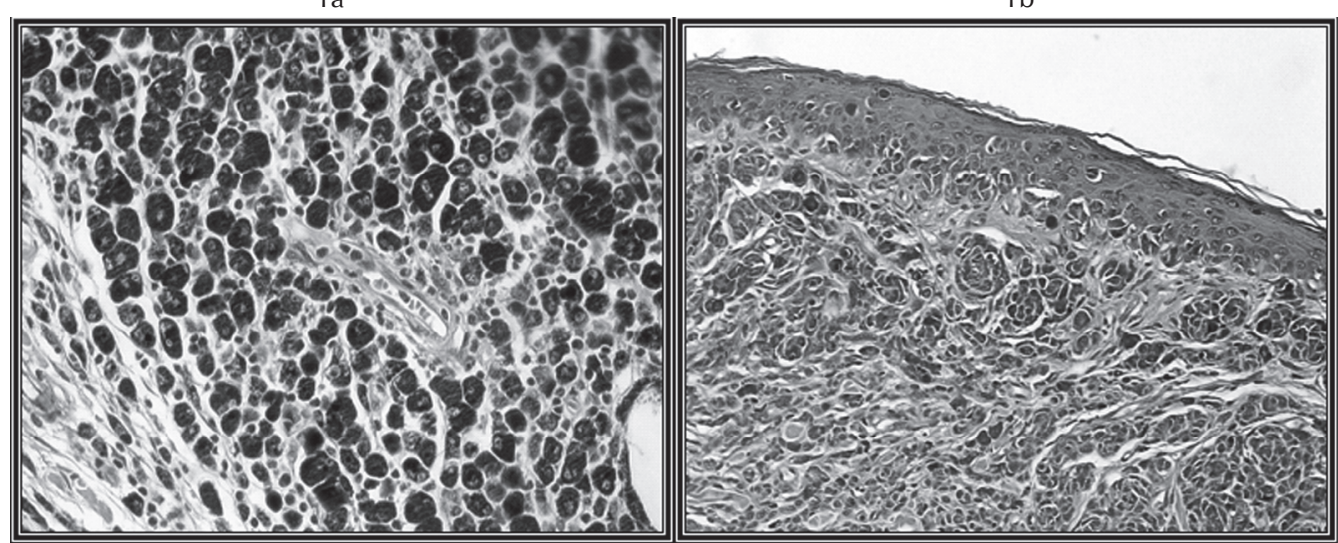

Figura 1a-Melanocitoma canino. Presença de moderado infiltrado celular acessório mononuclear de permeio às células redondas grandes intensamente pigmentadas (400X).

Figura 1b -Melanocitoma canino. Subtipo composto, com arranjo em tecas de células redondas grandes e fusiformes. Presença de pigmentação moderada e de epiderme moderadamente acantótica (200X).

$1 \mathrm{a}$

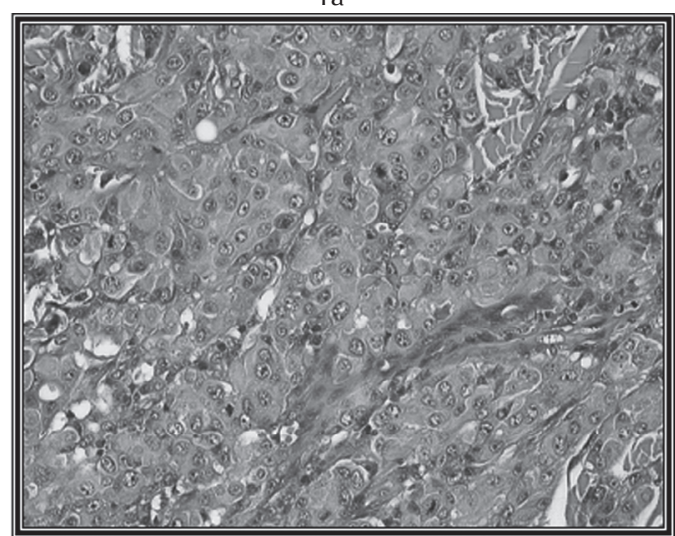

Figura 2a - Melanoma canino. Lesão amelanótica, com arranjo sólido de células Epitelióides. Presença de pleomorfismo e atividade mitótica (400X)

Figura 2b - Melanoma canino. Lesão melanótica, composta por células fusiformes em arranjo sólido e com pleomorfismos celular e nuclear. Presença de discreto estroma colagênico (400X) 
aderência a planos profundos); tempo de evolução da lesão (do surgimento até o diagnóstico); tratamento realizado; presença de recidiva, metástase ou outras alterações dermatológicas e/ou sistêmicas; tempo de evolução (do diagnóstico até o contato com o médico veterinário responsável) e progressão do caso clínico. Utilizou-se a estatística descritiva para a análise dos resultados obtidos e o teste "t" de Student, com nível de significância (a) de $5 \%$ para a comparação de médias (idade e diâmetro) entre os sexos dos animais acometidos por cada grupo de tumor, e entre os grupos de tumores (melanocitoma e melanoma).

\section{Resultados}

\section{Melanocitoma}

No presente estudo, constatou-se 39 casos $(67,2 \%)$ de neoplasias melanocíticas cutâneas benignas. A idade média dos animais acometidos foi de 7,41 \pm 3,2 anos. Observou-se o acometimento de cães desde um ano até os 15 anos de idade, sendo que a maioria dos casos (29 cães-74,4\%) ocorreu entre os seis e 11 anos de idade (Figura 3).

A proporção de machos e fêmeas acometida foi praticamente a mesma (1,05:1).
No entanto, a freqüência de acometimento em função da idade foi diferente. $\mathrm{Na}$ faixa de um a 11 anos, os machos foram mais acometidos em número absoluto (20 machos:16 fêmeas), mas a partir dos 13 anos, houve o acometimento exclusivo de fêmeas (três) (Figura 3). Não se observou diferença $(\mathrm{p}>0,05)$ entre os sexos com relação às médias de idade dos animais acometidos.

A maioria dos animais $(35-89,74 \%)$ possuía raça definida (Tabela 1 ). As oito raças mais acometidas, em ordem decrescente, foram: Schnauzer, Doberman, Rottweiler, Poodle, Pastor Alemão, Cocker Spaniel, Pinscher e Teckel.

A localização de 36 lesões $(85,71 \%)$ foi discriminada. As regiões anatômicas da cabeça, tronco e membros foram acometidas quase na mesma proporção (Figura 4). Dentre as regiões anatômicas, a região palpebral foi a mais acometida (Figura 5), seguida pela interdigital e torácica (Tabela 2). Trinta e cinco lesões (83,33\%) tiveram suas cores especificadas, sendo a cor preta a mais relatada (Tabela 3). A consistência foi especificada em 24 lesões $(57,14 \%)$, a maioria possuía consistência firme, embora lesões macias e friáveis também tenham sido detectadas (Tabela 4). Das lesões especificadas quanto à presença

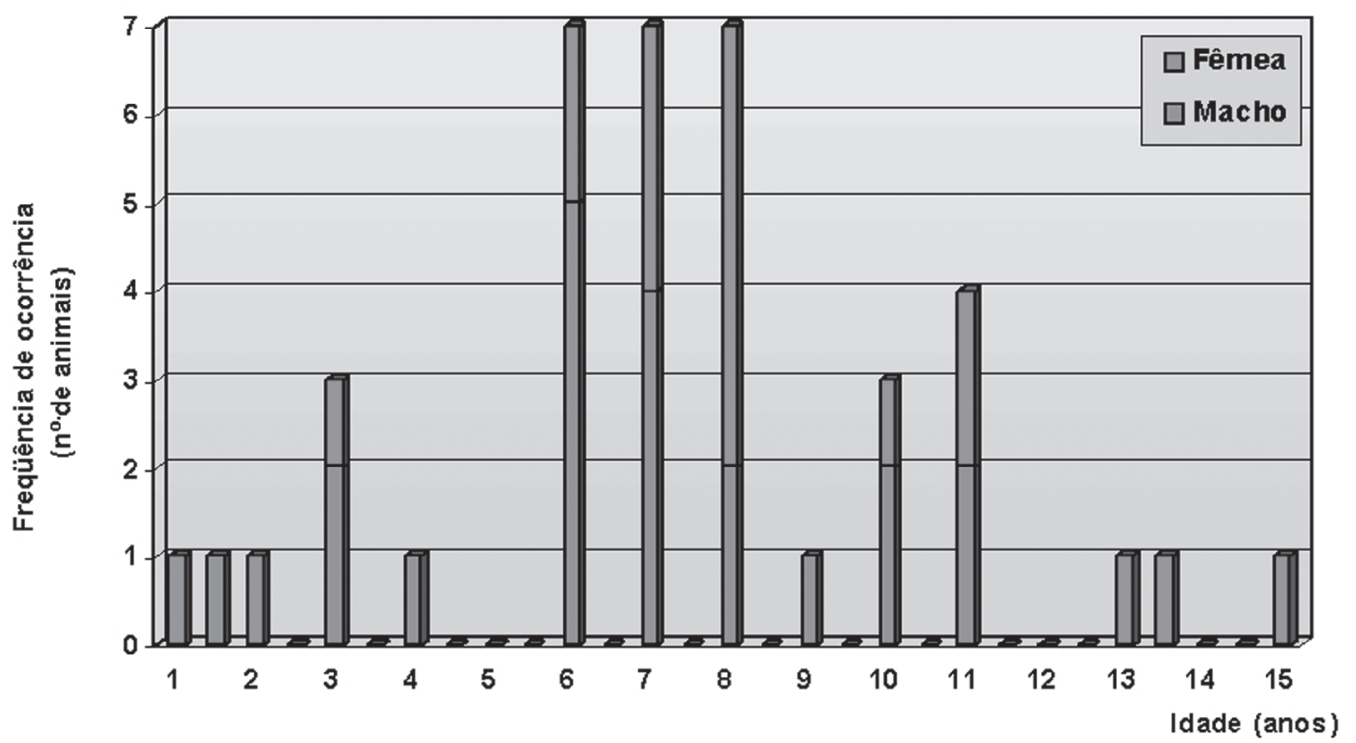

Figura 3 - Freqüência de acometimento dos cães pelo melanocitoma, segundo a idade e o sexo. $(n=39)$ 
Tabela 1 - Freqüência dos cães acometidos pelo melanocitoma, segundo a definição racial. $\mathrm{n}=39$, UFV, 2004

\begin{tabular}{cc}
\hline \hline Definição Racial & $\mathbf{N}(\%)$ \\
\hline \hline Schnauzer miniature & $5(12,82)$ \\
Doberman & $4(10,26)$ \\
S.R.D. & $4(10,26)$ \\
Rottweiler & $3(7,70)$ \\
Poodle & $3(7,70)$ \\
Pastor Alemão & $3(7,70)$ \\
Cocker Spaniel & $2(5,13)$ \\
Pinscher & $2(5,13)$ \\
Dachshund (Teckel) & $2(5,13)$ \\
Fox Paulistinha & $1(2,56)$ \\
Schnauzer gigante & $1(2,56)$ \\
Lhasa Apso & $1(2,56)$ \\
Yorkshire & $1(2,56)$ \\
Bloodhound & $1(2,56)$ \\
Labrador & $1(2,56)$ \\
Golden Retriever & $1(2,56)$ \\
Fila Brasileiro & $1(2,56)$ \\
Boxer & $1(2,56)$ \\
Chiuaua & $1(2,56)$ \\
Scoth Terrier & $1(2,56)$ \\
\hline \hline SRD = sem raça definida; N $=$ freqüência \\
absoluta; (\%) = frequência relativa
\end{tabular}

ou ausência de alopecia $(27$ - 64,29\%), todas revelaram-se alopécicas.

O tamanho tumoral variou de $1 \mathrm{~mm}$ a $6 \mathrm{~cm}$, com um diâmetro médio de 1,24 $\pm 1,2 \mathrm{~cm}$. Não se observou diferença $(p>0,05)$ entre os sexos, com relação ao tamanho médio das lesões. A maioria das lesões $(34-80,95 \%)$ não apresentou ulceração. Os aspectos macroscópicos lesionais mais freqüentes foram o papular (Figura 5) e o nodular, seguidos por aqueles em placa, mácula e mancha. Seis lesões papulares $(4 \%)$ e seis nodulares $(50 \%)$ apresentaram-se pedunculadas. Cinco pápulas $(19 \%)$ apresentaram-se com aspecto papilomatoso (Tabela 5).

Vinte e cinco lesões (60\%) foram informadas quanto à aderência a planos profundos. A maioria das lesões $(22-88 \%)$ não estava aderida, embora três lesões $(12 \%)$ tenham apresentado aderência.

A evolução das lesões, especificada em 17 casos $(43,6 \%)$, variou de 15 dias a dois anos (média de 7,8 \pm 8,6 meses e uma mediana e moda de 90 dias).

O tratamento de escolha realizado pelos médicos veterinários foi a excisão cirúrgica. Todas as lesões especificadas quanto à presença de recorrência (27 $64,29 \%$ ) não recidivaram em um tempo de seguimento clínico que variou de 30 dias a 5 anos (média de 14,7 \pm 14,2 meses e mediana de 12 meses). Lesões metastáticas não foram relatadas nos casos de melanocitoma discriminados $(25-64 \%)$. Houve o relato de um animal com múltiplas lesões de aspecto macroscópico semelhante ao do melanocitoma excisado, porém, sem comprovação histopatológica.

Nos 29 casos $(74,39 \%)$ com evolução clínica conhecida, o tempo de seguimento clínico variou de 30 dias a 5 anos, com média de 14,3 $\pm 13,6$ meses e mediana de 12 meses. Vinte e dois animais $(75,86 \%)$ apresentaram-se hígidos após um período compreendido entre 30 dias a 5 anos (média de $13,5 \pm 13,4$ meses e mediana de 12 meses). Cinco cães $(17,24 \%)$ evoluíram para óbito em um período de 3 meses, de acordo com o relato dos médicos veterinários, relacionado às seguintes enfermidades: fibrossarcoma ( $1-20 \%)$, tumor de mama e melanoma na região torácica $(1-20 \%)$, tumor de mama (1 - 20\%), insuficiência renal (IR) $(1-20 \%)$ e leptospirose $(1-20 \%)$. Em um caso $(3,45 \%)$, o animal não teve a causa da morte especificada e, em outro $(3,45 \%)$, o cão foi eutanasiado devido às péssimas condições de vida relacionadas à associação com o melanoma no metatarso.

Todos os casos com evolução clínica conhecida e sem o melanoma concomitante, encontraram-se hígidos até o último contato com o médico veterinário responsável. Metástases não foram comprovadas e 


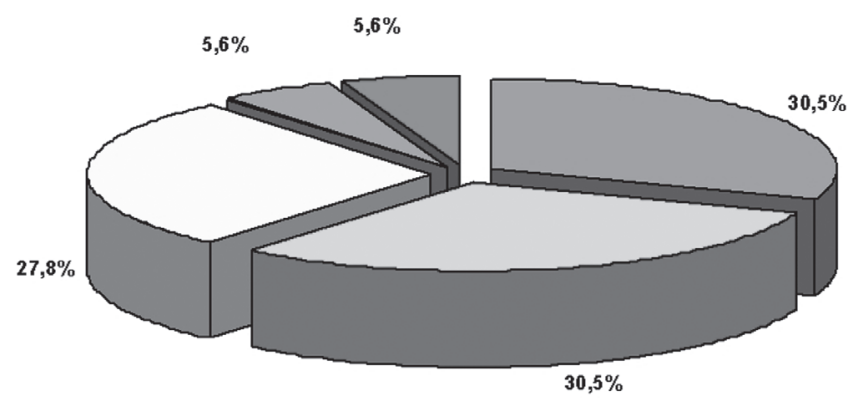

$\square$ Cabeça $\square$ Tronco $\square$ Membros $\square$ Cervical $\square$ Perianal

Figura 4 - Distribuição anatômica dos melanocitomas em cães. $n=36$

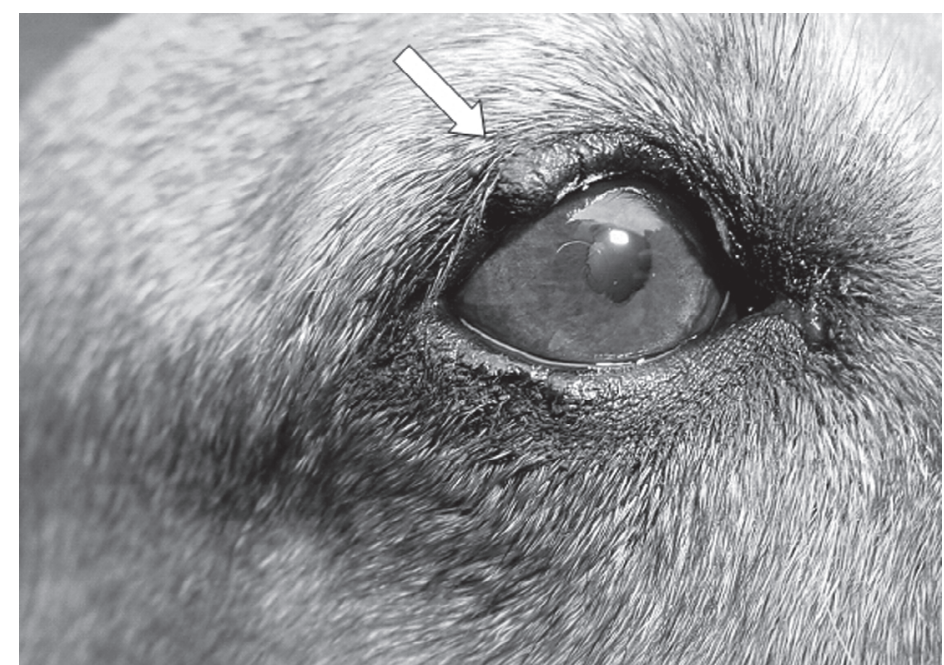

Figura 5 - Melanocitoma canino. Lesão papular hiperpigmentada na pálpebra superior (seta)

recidivas não foram observadas.

Em 27 casos (69,4\%) obteve-se a informação sobre a presença de outras alterações dermatológicas ou sistêmicas. Dezessete animais (63\%) não apresentaram qualquer alteração sistêmica ou cutânea. No entanto, em 10 animais (37\%), foram observadas as seguintes alterações: hipotiroidismo $(1-10 \%)$, carcinoma espino celular abdominal $(1-10 \%)$, fibrossarcoma $(1-10 \%)$, tumor de mama e melanoma (1 $10 \%)$, melanoma $(1-10 \%)$, tumor de mama $(1-10 \%)$, IR $(1-10 \%)$, carcinoma pouco diferenciado de leito ungueal (1 - 10\%), papilomas pelo corpo $(1-10 \%)$ e epitelioma sebáceo palpebral $(1-10 \%)$.

\section{Melanoma}

No atual trabalho, 19 casos $(32,8 \%)$ de lesões melanocíticas cutâneas foram malignos. A faixa etária dos animais acometidos variou de quatro a 16 anos, com idade média de 10,26 \pm 3,5 anos. Houve uma concentração maior de casos (11 cães - 58\%) entre os nove e 13 anos de idade (Figura 6).

O melanoma ocorreu em 11 cães machos $(58 \%)$ e em oito fêmeas (42\%). Na faixa etária de quatro a sete anos, a proporção de machos acometidos foi maior (4:1), não tendo sido observada esta diferença após os nove anos de idade (Figura 6). Não se observou diferença $(p>0,05)$ entre os sexos com relação às médias de idade dos animais acometidos, no entanto, a idade média dos cães com melanoma foi maior $(p<0,05)$ que os animais com melanocitoma. 
Tabela 2 - Distribuição anatômica regional dos melanocitomas em cães. n=36, UFV, 2004

\begin{tabular}{cccc}
\hline Localização & Número de Lesões & Percentual Regional & Percentual do Total \\
\hline \hline Cabeça & Total 11 & $\mathbf{1 0 0}$ & $\mathbf{3 0 , 5}$ \\
\hline Palpebral & 10 & 91 & 27,8 \\
Pina & 1 & 9 & 2,7 \\
\hline \hline Cervical & Total 2 & $\mathbf{1 0 0}$ & $\mathbf{5 , 6}$ \\
\hline \hline Tronco & Total 11 & $\mathbf{1 0 0}$ & $\mathbf{3 0 , 5}$ \\
\hline Torácica & 5 & 45,4 & 13,9 \\
Abdominal & 3 & 27,3 & 8,3 \\
Lombossacral & 3 & 27,3 & 8,3 \\
\hline \hline Membros & Total 10 & $\mathbf{1 0 0}$ & $\mathbf{2 7 , 8}$ \\
\hline \hline Interdigital & 6 & 60 & 16,6 \\
Membro pélvico & 2 & 20 & 5,6 \\
Membro torácico & 1 & 10 & 2,8 \\
Dígito & 1 & 10 & 2,8 \\
\hline \hline Perianal & Total 2 & $\mathbf{1 0 0}$ & $\mathbf{5 , 6}$ \\
\hline \hline
\end{tabular}

Tabela 3 - Cor das lesões melanocíticas benignas caninas, de acordo com a freqüência de ocorrência. $\mathrm{n}=35$, UFV, 2004

\begin{tabular}{cc}
\hline \hline Cor das lesões & $\mathbf{N}(\%)$ \\
\hline \hline Preta & $31(88,57)$ \\
Marrom & $3(8,57)$ \\
Azulada & $1(2,9)$ \\
\hline \hline & N = frequêencia absoluta; \\
$(\%)=$ frequêencia relativa
\end{tabular}

Dezesseis cães $(84,2 \%)$ possuíam raça definida (Tabela 6 ). As raças mais acometidas foram: Rottweiler, Pinscher, Cocker Spaniel, Airedale Terrier, Pastor Alemão e Doberman.

Houve o relato de dois casos em que os animais apresentaram lesões múltiplas e multicêntricas, porém, sem confirmação histopatológica de melanoma. Portanto, as lesões foram consideradas todas únicas. ${ }^{14}$

A localização das lesões foi obtida em 16 casos $(84,21 \%)$. As lesões ocorreram com maior freqüência na cabeça, sendo a região labial a mais acometida (Tabela 7). As pálpebras foram o segundo local mais acometido, porém, a região digital foi acometida na mesma proporção das demais regiões anatômicas. Além disso, a localização
Tabela 4 - Consistência das lesões melanocíticas benignas em cães, de acordo com a freqüência de ocorrência. $n=24$, UFV, 2004

\begin{tabular}{cc}
\hline $\begin{array}{c}\text { Consistência } \\
\text { das lesões }\end{array}$ & $\mathbf{N}(\%)$ \\
\hline \hline Firme & $18(75,0)$ \\
Macia & $5(20,8)$ \\
Friável & $1(4,2)$ \\
\hline \hline $\begin{array}{c}\mathrm{N}=\text { freqüência absoluta; } \\
(\%)=\text { frequência relativa }\end{array}$
\end{tabular}

precisa dos tumores digitais não foi conhecida, não permitindo a associação de origem subungueal e malignidade. No presente estudo, o melanoma labial acometeu as raças Cocker Spaniel, Yokshire e Pastor Alemão.

Quinze lesões $(78,95 \%)$ tiveram suas cores especificadas. A cor preta foi a mais mencionada, seguida pela rósea, cinza de várias tonalidades e marrom (Tabela 8). A consistência à palpação foi obtida em 12 lesões $(63,16 \%)$, sendo a firme a mais referida, entretanto, lesões friáveis e macia também foram relatadas no atual trabalho (Tabela 9). O diâmetro médio dos melanomas foi de 2,54 $\pm 2,0 \mathrm{~cm}$, variando de $5 \mathrm{~mm}$ a $10 \mathrm{~cm}$ e a maioria das lesões (15- 
Tabela 5 - Freqüência de ocorrência dos aspectos lesionais nos melanocitomas em cães. $\mathrm{N}=42$, UFV, 2004

\begin{tabular}{|c|c|}
\hline Aspecto lesional & $\mathbf{N}(\%)$ \\
\hline Pápula & $26(62,0)$ \\
\hline Nódulo & $12(28,57)$ \\
\hline Placa & $2 \quad(4,76)$ \\
\hline Mácula & $1 \quad(2,38)$ \\
\hline Mancha & $1 \quad(2,38)$ \\
\hline
\end{tabular}

Tabela 6 - Freqüência dos cães acometidos pelo melanoma, segundo a definição racial. $n=1$, UFV, 2004

\begin{tabular}{cc}
\hline \hline RAÇA & $\mathrm{N}(\%)$ \\
\hline \hline S.R.D. & $3(15,8)$ \\
Rottweiler & $2(10,5)$ \\
Pinscher & $2(10,5)$ \\
Cocker Spaniel & $2(10,5)$ \\
Airedale Terrier & $2(10,5)$ \\
Pastor Alemão & $2(10,5)$ \\
Doberman & $2(10,5)$ \\
Schnauzer gigante & $1(5,30)$ \\
Teckel & $1(5,30)$ \\
Husky Siberiano & $1(5,30)$ \\
Yorkshire & $1(5,30)$ \\
\hline \hline
\end{tabular}

$\mathrm{SRD}=$ sem raça definida;

$\mathrm{N}=$ frequência absoluta;

$(\%)=$ frequência relativa

$78,95 \%$ ) estava ulcerada.

Não se observou diferença $(p>0,05)$

entre os sexos, com relação ao tamanho médio das lesões, porém, entre os grupos de tumores, o diâmetro médio dos melanomas foi maior $(p<0,05)$.

$\mathrm{O}$ aspecto lesional foi especificado em 16 lesões $(84,21 \%)$. A forma nodular foi a mais observada, seguida pela papular e tumoral. Um nódulo e uma pápula apresentaram-se pedunculados, e outro nódulo apresentou-se com aspecto papilomatoso (Tabela 10).

Dez lesões $(52,63 \%)$ foram discriminadas quanto à presença ou ausência de aderência a planos profundos. Seis lesões
(60\%) não estavam aderidas, entretanto, quatro $(40 \%)$ apresentaram aderência.

O tempo de evolução das lesões, especificada em 10 casos (52,63\%), variou de 15 dias a 2,5 anos (média de 6,3 \pm 9 meses, mediana de 3,5 meses e moda de 15 dias).

A maioria das lesões foi tratada por excisão cirúrgica, tendo alguns casos (8 $42,11 \%$ ) sofrido apenas biópsia incisional. A informação sobre recidivas foi obtida em 11 casos $(57,89 \%)$. Duas lesões $(18,18 \%)$ recidivaram: uma após 10 dias e outra após 90 dias. Em nove casos (81,82\%), não se observou recidiva. Contudo, desses casos, seis $(66,67 \%)$ evoluíram para óbito em um tempo médio de 4,6 \pm 5 meses (mediana de 90 dias) ou logo após o procedimento cirúrgico.

Em seis animais $(31,58 \%)$, utilizandose de outros recursos diagnósticos (ex: RX e ultrassonografia), foram detectados sinais de provável metástase para baço $(1-16,7 \%)$, pele e pulmão $(2-33,3 \%)$ e linfonodo $(2-33,3 \%)$, mas sem confirmação histopatológica ou necroscópica, pois os casos clínicos foram atendidos em clínicas particulares onde raramente se faz necropsia. Portanto, não houve lesões metastáticas comprovadas no presente trabalho.

Nos 12 casos $(63,16 \%)$ com evolução clínica conhecida, o tempo médio de evolução foi de $9 \pm 7,5$ meses e mediana de 7,5 meses. A condição neoplásica acarretou, por agravamento do quadro clínico, a eutanásia de seis animais $(50 \%)$ e o óbito natural de um $(8,33 \%)$, após um tempo médio de $5 \pm 4$ meses (mediana de 90 dias). Quatro cães (33,33\%) apresentaram-se hígidos até o contato telefônico, após um tempo médio de $17 \pm 5,4$ meses (mediana de 14 meses). Um animal (8,33\%) sofreu eutanásia relacionada a uma outra neoplasia (fibrossarcoma) depois de 3 meses do diagnóstico.

Dos 13 casos $(68,42 \%)$ especificados a respeito da presença de outras alterações sistêmicas ou cutâneas, 11 animais (84,62\%) apresentaram alterações, tais como: dispnéia e anorexia $(1-9 \%)$; demodiciose, tumor de 


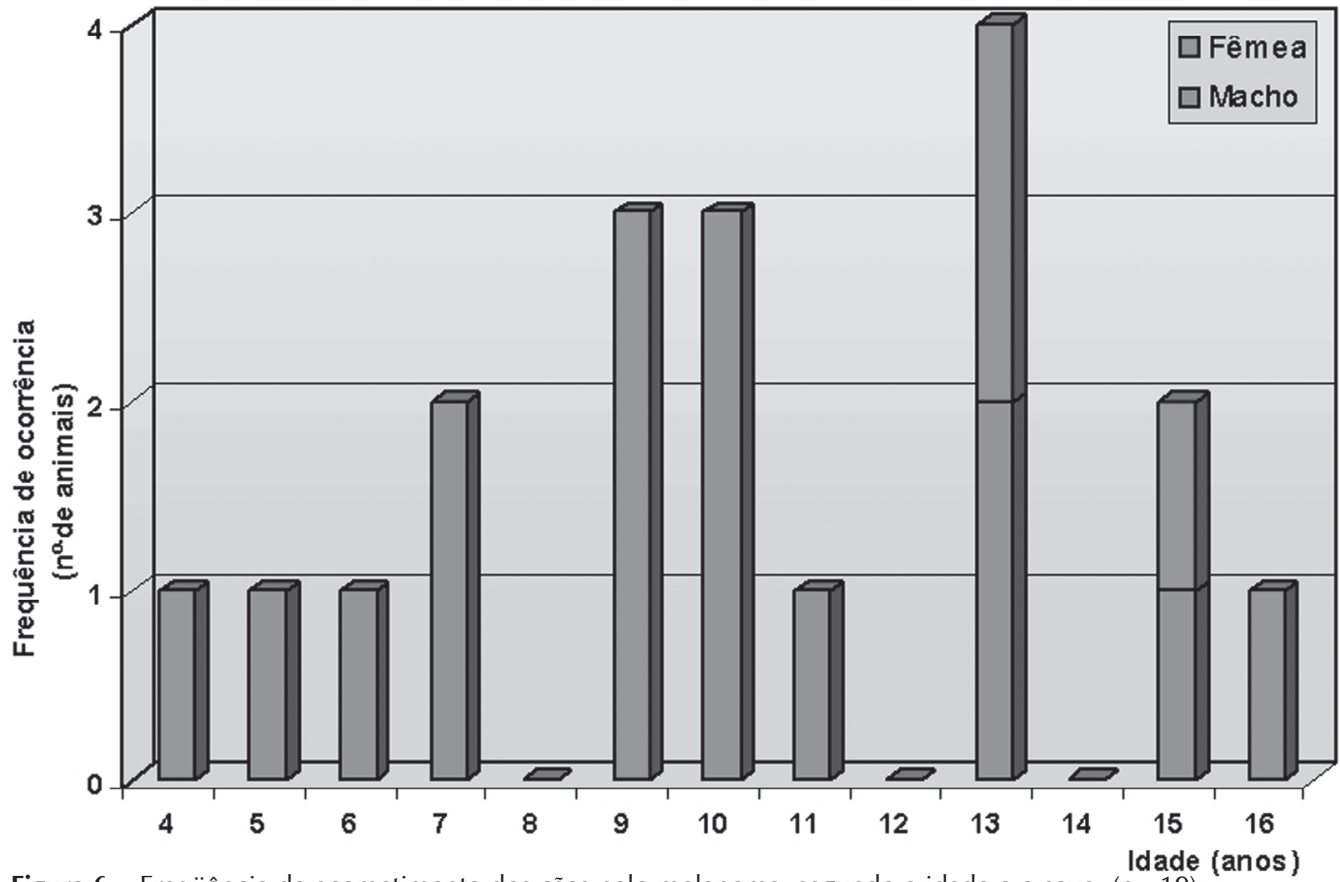

Figura 6 - Freqüência de acometimento dos cães pelo melanoma, segundo a idade e o sexo. $(n=19)$

Tabela 7 - Distribuição anatômica regional dos melanomas em cães. $(n=16)$, UFV, 2004

\begin{tabular}{cccc}
\hline Localização & Número de Lesões & Percentual Regional & Percentual doTotal \\
\hline \hline Cabeça & Total 9 & $\mathbf{1 0 0}$ & $\mathbf{5 6 , 2 5}$ \\
\hline \hline Labial & 5 & 55,6 & 31,25 \\
Palpebral & 2 & 22,2 & 12,05 \\
Mentoniana & 1 & 11,1 & 6,25 \\
Plano nasal & 1 & 11,1 & 6,25 \\
\hline \hline Cervical & Total 1 & $\mathbf{1 0 0}$ & $\mathbf{6 , 2 5}$ \\
\hline Tronco & Total 2 & $\mathbf{1 0 0}$ & $\mathbf{1 2 , 5 0}$ \\
\hline \hline Torácica & 1 & 50 & 6,25 \\
Abdominal & 1 & 50 & 6,25 \\
\hline \hline Membros & Total 3 & $\mathbf{1 0 0}$ & $\mathbf{1 8 , 7 5}$ \\
\hline Membro & 1 & 33,3 & 6,25 \\
Pélvico & 1 & 33,3 & 6,25 \\
Digital & 1 & 33,3 & 6,25 \\
Interdigital & Total 1 & $\mathbf{1 0 0}$ & $\mathbf{6 , 2 5}$ \\
\hline Perianal & & & \\
\hline \hline
\end{tabular}

mama e anorexia $(1-9 \%)$; tumor de mama e melanocitoma $(1-9 \%)$; dispnéia, edema de membro e melanocitoma $(1-9 \%)$; hemangioma cavernoso $(1-9 \%)$, fibrossarcoma $(1-9 \%)$, nódulos pelo corpo e derrame pleural $(1-9 \%)$, IR e insuficiência cardíaca (IC) (1- 9\%); hipotiroidismo (1 $9 \%)$; IC $(1-9 \%)$ e piodermite $(1-9 \%)$. 
Tabela 8 - Cor dos melanomas em cães, segundo a freqüência de ocorrência. $(n=15)$, UFV, 2004

\begin{tabular}{cc}
\hline \hline Cor das lesões & $\mathbf{N}(\%)$ \\
\hline \hline Preta & $7(46,7,7)$ \\
Rósea & $4(26,7)$ \\
Cinza & $3(20,0)$ \\
Marrom & $1(6,7)$ \\
\hline \hline
\end{tabular}

$\mathrm{N}=$ freqüência absoluta; $(\%)=$ freqüência relativa

Tabela 9 - Consistência dos melanomas em cães, segundo a freqüência de ocorrência. $n=12$, UFV, 2004

\begin{tabular}{cc}
\hline \hline $\begin{array}{c}\text { Consistência } \\
\text { das lesões }\end{array}$ & $\mathbf{N}(\%)$ \\
\hline \hline Firme & $8(66,7)$ \\
Friável & $3(25)$ \\
Macia & $1(8,3)$ \\
\hline \hline $\begin{array}{l}\text { N = frequência absoluta; } \\
(\%)=\text { frequêencia relativa }\end{array}$
\end{tabular}

Tabela 10 - Freqüência de ocorrência do aspecto lesional dos melanomas em cães. $n=16$, UFV, 2004

\begin{tabular}{lc}
\hline \hline $\begin{array}{l}\text { Aspecto } \\
\text { lesional }\end{array}$ & $\mathbf{N}^{\text {o. }}(\mathbf{\%})$ \\
\hline \hline Nodular & $13(81,25)$ \\
Papular & $2(12,50)$ \\
Tumoral & $1(6,25)$ \\
\hline \hline
\end{tabular}

$\mathrm{N}=$ freqüência absoluta;

$(\%)=$ freqüência relativa

Dois animais $(15,38 \%)$ não apresentaram qualquer alteração.

\section{Discussão}

\section{Melanocitoma}

Nos trabalhos de Bolon, Calderwood e Hall ${ }^{17}$, Goldschmidt ${ }^{6}$ e Scott, Miller e Griffin ${ }^{9}$ a maioria das neoplasias melanocíticas cutâneas também foi benigna, no entanto, a proporção de lesões benignas foi maior que a observada pelos autores do presente estudo.

A idade média dos animais acometidos foi maior em alguns estudos ${ }^{7,14,17}$ e menor em outros ${ }^{18,19}$. No entanto, no atual estudo, o pico de incidência de casos entre os cinco e 11 anos de idade foi semelhante ao observado por Goldschmidt e Hendrick ${ }^{5}$ e Goldschmidt e Shofer ${ }^{7}$ faixa etária na qual os animais estão mais suscetíveis às doenças neoplásicas ${ }^{9}$ De forma semelhante também a relatos anteriores ${ }^{5,17,19}$, neste estudo, animais muito jovens foram diagnosticados com melanocitoma.

Não se observou predisposição sexual nesta pesquisa, corroborando a maioria dos achados anteriores 5, 7,13,17, embora cães machos tenham sido acometidos em maior número no estudo de Orkin e Schwartzman ${ }^{19}$. A diferença absoluta observada na freqüência de acometimento entre machos e fêmeas em função da idade não foi mencionada anteriormente, todavia, a reduzida casuística do presente trabalho não permite uma conclusão a esse respeito. Também na literatura consultada, não foi mencionada a ausência de diferença estatística entre os sexos com relação às médias de idade dos animais acometidos.

A maioria dos casos de melanocitoma ocorreu em cães com raça definida, sendo que algumas dessas raças conferem com as citadas por Bolon, Calderwood e Hall ${ }^{17}$. Porém, nem todas coincidem com aquelas relatadas por Kraft e Frese ${ }^{18}$, Goldschmidt e Shofer ${ }^{7}$, Ogilvie e Moore ${ }^{13}$ e Goldschmidt e Hendrick ${ }^{5}$. Esse fato provavelmente reflete as diferenças na predileção pelos proprietários por determinadas raças nas diversas regiões e épocas.

A localização, as cores, a consistência, a presença de alopecia e o aspecto clínico das lesões conferem com relatos anteriores. ${ }^{6,7,8,13}$ Entretanto, a variação de diâmetro foi maior que a observada anteriormente. ${ }^{7,8} \mathrm{~A}$ literatura consultada não faz menção sobre a ausência diferença estatística entre os sexos, com relação ao tamanho médio das lesões.

A maioria das lesões não estava ulcerada e nem aderida, assim como achados passados. ${ }^{6,7,8}$ A ulceração observada na minoria das lesões deve-se, provavelmente, 
ao autotrauma ou à inflamação secundária de acordo com Vail e Withrow ${ }^{20}$. Segundo os mesmos autores, os melanocitomas apresentam histórico de crescimento lento, variando de semanas a meses, assim como constatado na maioria das lesões do presente estudo.

O tempo médio de seguimento clínico deste estudo foi menor que o observado por Bostock ${ }^{14} \mathrm{em}$ seu estudo. Esse fato pode ser justificado pela presença de muitos casos recentes (2003/2004) no atual trabalho.

De acordo com Feeney, Hayden e Wallace ${ }^{21}$, os cães são a espécie doméstica que mais apresenta múltiplos tumores primários, sejam eles benignos, malignos ou ambos. Este fato justifica a presença de outras alterações dermatológicas ou sistêmicas em alguns dos casos de melanocitoma do presente estudo.

Confirmando o bom prognóstico dos melanocitomas ${ }^{5,17}$, neste estudo, todos os casos com evolução clínica conhecida e sem o melanoma concomitante, encontraram-se hígidos até o último contato com o médico veterinário responsável. Esses achados contrapõem-se aos de Bostock ${ }^{14}$, que em seu estudo, observou que $8 \%$ dos cães com lesões cutâneas melanocíticas benignas desenvolveram metástases ou recidivas inoperáveis que resultaram no óbito desses animais. A transformação de lesões melanocíticas benignas em malignas, nos humanos, ocorre em uma pequena porcentagem de tumores. A mais importante categoria de lesões precursoras são os nevos displásicos. Múltiplos nevos displásicos em um indivíduo estão associados com um maior risco de melanoma. Outras lesões precursoras em humanos incluem os nevos melanocíticos congênitos gigantes ${ }^{10}$, mas apenas um único caso de transformação maligna de uma lesão congênita similar em um Golden Retriever foi relatada. ${ }^{4}$ No geral, com exceção dos cavalos tordilhos, transformação maligna de lesões benignas é muito incomum nos animais. $^{4}$

\section{Melanoma}

A porcentagem de casos de melanoma neste estudo foi maior que a observada anteriormente ${ }^{2,11}$. Entretanto, a idade média dos animais acometidos foi menor que a relatada por Bolon, Calderwood e Hall ${ }^{17}$ e semelhante àquela observada por Bostock ${ }^{14}$ e Goldschmidt e Shofer ${ }^{7}$. Semelhante também a literatura ${ }^{5}$ está a maior incidência de casos entre os nove e 13 anos.

No estudo de Conroy ${ }^{3}$ os machos foram mais acometidos que as fêmeas, achado também observado neste trabalho, porém, não significativo, corroborando a maioria dos autores de que a predisposição sexual não existe. ${ }^{6,7} \mathrm{~A}$ literatura não cita a diferença absoluta observada na freqüência de acometimento entre machos e fêmeas em função da idade, assim como a ausência de diferença $(p>0,05)$ entre os sexos com relação às médias de idade dos animais acometidos. No entanto, o achado de que a idade média dos cães acometidos pelos melanomas é estatisticamente maior foi citado por Orkin e Schwartzman ${ }^{19}$.

As raças acometidas pelo melanoma não coincidem totalmente com aquelas relatadas em trabalhos anteriores. ${ }^{7,8,17}$ Mais uma vez, esse fato, provavelmente, reflete as diferenças na predileção pelos proprietários por determinadas raças nas diversas regiões e épocas. De acordo com a literatura, cães com pele intensamente pigmentada, como os Schnauzer e os Scottish Terrier têm um maior risco de desenvolverem o melanoma. ${ }^{4,9}$

A maioria dos melanomas apresentouse solitário, concordando com achados anteriores. ${ }^{1}$ Goldschmidt e Shofer ${ }^{7}$ acrescentam que são solitários principalmente aqueles de origem labial.

No presente estudo, a região labial a mais acometida. Alguns autores apontam, além dos lábios, outras junções mucocutâneas (prepúcio, vulva, ânus e focinho) como locais de maior acometimento pelos melanomas., ${ }^{4,17}$ Outros autores ainda indicam também as pálpebras e os dígitos (particularmente o leito ungueal) como locais de predileção. ${ }^{8}$ 
Essa predileção não foi confirmada pelo presente estudo, pois as pálpebras foram o segundo local mais acometido, porém, a região digital foi acometida na mesma proporção das demais regiões anatômicas. Além disso, a localização precisa dos tumores digitais não foi conhecida, não permitindo a associação de origem subungueal e malignidade. De acordo com a literatura, o melanoma subungueal é tido como a segunda neoplasia digital mais comum depois do carcinoma de células escamosas e o Golden Retriever como o cão com o maior risco de desenvolver o melanoma subungueal. ${ }^{4}$ O Setter Irlandês, o Chihuahua, o Golden Retriever e o Cocker Spaniel possuem maior risco de desenvolverem o melanoma labial. ${ }^{4} \mathrm{~A}$ razão para a predileção racial não está esclarecida, mas sustenta a hipótese de que estes tumores nos cães podem apresentar predisposição genética. ${ }^{2}$

As cores, a consistência, o tamanho, o aspecto macroscópico e a presença de alopecia, ulceração e aderência das lesões melanóticas malignas citadas assemelham-se aos dados dispostos na bibliografia. ${ }^{13,3,6,7,8}$

$\mathrm{Na}$ literatura, a ausência de relação entre o tamanho médio da lesão e o sexo não foi mencionada. Entre os grupos de tumores, o diâmetro médio dos melanomas foi significativamente maior. Portanto, é razoável assumir que quanto maior o diâmetro médio da lesão pigmentada, maior a chance de malignidade. De acordo com Harvey ${ }^{22}$ e Bolon, Calderwood e Hall ${ }^{17}$, o diâmetro dos tumores e o alto índice de mitose são indicadores úteis para estabelecer o prognóstico do melanoma canino.

A partir da avaliação da mediana e da moda, observou-se que as lesões malignas evoluíram mais rapidamente em relação às benignas no presente estudo, assim como na literatura. ${ }^{6,7}$

As opções de tratamento para o melanoma, além da ressecção cirúrgica radical, incluem radioterapia 23,24 , fotocoagulação ${ }^{15,25}$, quimioterapia ${ }^{26}$, imunoterapia e geneterapia ${ }^{11,27,28}$. Nenhum animal da casuística deste estudo foi submetido a protocolos quimioterápicos.
O fato da maioria dos animais ter evoluído para óbito associado aos casos sem informações a respeito de lesões recorrentes, contribuiu para que a porcentagem de recidivas neste estudo fosse baixa quando comparada à do estudo de Bolon, Calderwood e Hall ${ }^{17}$, no qual todas as lesões malignas recidivaram. Ainda no estudo de Bolon, Calderwood e Hall ${ }^{17}$, metástases foram observadas em $57 \%$ dos casos de melanoma, mas teria sido ainda maior, segundo os autores, se todos os animais tivessem sido necropsiados. Da mesma forma, no atual estudo, se todos os animais que não sobreviveram tivessem sido necropsiados, provavelmente, lesões metastáticas teriam sido observadas.

A maioria dos animais apresentou alterações sistêmicas ou cutâneas concomitantemente ao melanoma. Bolon, Calderwood e Hall ${ }^{17}$, em seus estudos, observaram que $1 \%$ dos cães apresentou, simultaneamente, lesão oral maligna e benigna cutânea. Porém, não foram observadas, como ocorrido em dois casos da atual pesquisa, lesões cutâneas benignas e maligna no mesmo animal. Dos animais domésticos, o cão é a espécie na qual freqüentemente ocorrem múltiplos tumores primários, podendo a combinação incluir um maligno e um benigno ou dois malignos. ${ }^{21}$

O tempo médio de evolução e a mediana foram ambos menores que o observado por Bostock ${ }^{14}$, assim como o tempo de sobrevida foi menor que o relatado por Bolon, Calderwood e Hall ${ }^{17}$. Uma alternativa para se aumentar o tempo de sobrevida, seria a associação da quimioterapia com a excisão cirúrgica radical, com ampla margem de segurança (cerca de 1 a $3 \mathrm{~cm}$ ), ou com a criocirurgia ou radioterapia, quando a ablação não puder ser completa. ${ }^{14}$

O presente trabalho, apesar de possuir muitos casos com seguimento clínico desconhecido, apresentou porcentagem de casos que resultaram em morte pela progressão natural da doença ou por eutanásia, semelhante quando comparado ao 
achado de Bolon, Calderwood e Hall ${ }^{17} \mathrm{e}$ maior que o observado por Bostock ${ }^{14}$.

A porcentagem de casos curados pelo procedimento cirúrgico neste estudo foi semelhante à observada por Bolon, Calderwood e Hall ${ }^{17}$ (34,8\%), porém menor do que a observada por Bostock ${ }^{14}$ (55\%). Todavia, essa observação não invalida o prognóstico ruim associado ao melanoma.

A partir dos resultados, pode-se concluir em relação aos Melanocitomas: a maioria das neoplasias melanocíticas cutâneas foram benignas; acometeram desde animais jovens a idosos; os animais mais acometidos foram os da raça Schnauzer e Doberman, seguidos por aqueles sem raça definida; a maioria das lesões apresentou-se solitária, alopécica, enegrecida, firme à palpação, não ulcerada, não aderida, com diâmetro médio de $1,2 \mathrm{~cm}$, aspecto papular e localizadas com maior freqüência na região palpebral, interdigital e torácica; apresentaram um bom prognóstico e cura pelo tratamento cirúrgico.

A partir dos resultados, pode-se concluir em relação aos Melanomas: acometeram animais de meia idade a idosos, porém com idade média superior aos portadores dos melanocitomas; a maioria das lesões apresentou-se solitária, alopécica, preta, firme, ulcerada, não aderida, com aspecto clínico nodular, de diâmetro médio maior que os melanocitomas e localizadas mais freqüentemente na região labial e palpebral; a maioria das lesões esteve associada a um prognóstico ruim, embora a cura pelo procedimento cirúrgico tenha ocorrido em poucos casos. Portanto, o diagnóstico precoce dos melanomas é fundamental. Quando esse tumor é detectado tardiamente, raramente a excisão cirúrgica é curativa e metástases já podem ser detectadas em linfonodos regionais ${ }^{4}$. Dessa forma, é importante que durante o exame dermatológico de qualquer animal, principalmente daqueles de meia idade a idosos, o médico veterinário atente para lesões hiperpigmentadas e alerte os proprietários para o exame periódico de seus cães. De acordo com a literatura, nenhuma característica clínica distingue as proliferações melanocíticas benignas das malignas 7,8,14,17. No entanto, através dos diversos achados do presente estudo, observou-se que a chance de uma lesão melanocítica cutânea ser maligna é maior quando localizada nos lábios e nas pálpebras, e quando se apresenta ulcerada e com diâmetro maior que $2,5 \mathrm{~cm}$. Nestes casos aconselha-se a realização da excisão cirúrgica radical com ampla margem. As lesões melanocíticas papulares ou maculares, não ulceradas, por segurança, devem ser submetidas à biópsia excisional, sujeita à ampliação da margem cirúrgica se o exame histopatológico for sugestivo de lesão maligna.

\section{Cutaneous melanocytic neoplasms in dogs: retrospective study of 58 cases (1996-2004)}

\section{Abstract}

Thirty nine cases (42 lesions) of melanocytoma and nineteen cases (19 lesions) of canine cutaneous melanoma were analyzed. The melanocytomas affected the young animals as well as the old ones, without a sexual predisposition. The most affected dogs were the ones of the Schnauzer and Doberman breed, being followed by those without a defined breed. Most lesions appeared solitarily and located in the eyelid, interdigital and thorax regions. In general, the lesions were papuled, no haired, non adhering, black colored, with a firm consistency and a mean diameter of $1,2 \mathrm{~cm}$. Recurrence and metastases were not seen. Such fact confirms the good prognostic associated to melanocytomas. The melanomas affected the older animals, without a sexual predisposition. The most affected dogs were the ones without a defined breed, being
Key words: Melanocitics tumors. Melanoma. Melanocytoma. Dog. 
followed by those of the Rottweiler, Pinscher, Cocker Spaniel and Airedale breeds. The lesions appeared solitarily and located on the lips and eyelid. Most tumors were ulcerated and nodular, with a firm consistency, with a mean diameter of $2,5 \mathrm{~cm}$. Some lesions presented recurrence. Metastases could not be proven. Among the cases with a known clinical segment, some were cured through a surgical procedure, however, the majority died, probably related to a neoplastic disease, confirming the bad prognostic related to melanoma.

\section{Referências}

1 GARMA-AVIÑA, A.; VALLI, V. E.; LUMSDEN, J. H. Cutaneous melanomas in domestic animals. Journal of Cutaneous Pathology, v. 8, p. 3-24, 1981.

2 MODIANO, J. F; RITT, M. G.; WOJCIESZYN, J. The molecular basis of canine melanoma: pathogenesis and trends in diagnosis and therapy. Journal of Veterinary Intern Medicine, v. 13, p. 163-174, 1999.

3 CONROY, J. D. Melanocytic tumors of domestic animals. Archives of Dermatology, v. 96, p. 372-380, 1967.

4 SMITH, S. H.; GOLDSCHMIDT, M. H.; McMANUS, P. M. A comparative review of melanocytic neoplasms. Veterinary Pathology, v. 39, n. 6, p. 651-678, 2002.

5 GOLDSCHMIDT, M.H.; HENDRICK, M.J. Tumors of the skin and soft tissues. In: Meuten, D.J. Tumors in domestics animals. 4. ed. Iowa:lowa State Press, 2002. 788 p.

6 GOLDSCHMIDT, M. H. Pigmented lesions of the skin. Clinics in Dermatology, v. 12, p. 507-514, 1994.

7 GOLDSCHMIDT, M. H.; SHOFER, F. S. Skin tumors of the dog \& cat. Dermatology. 1 ed. Oxford: Pergamon Press, 1992. $316 \mathrm{p}$

8 GROSS, T. L.; IHRKE, P. J.; WALDER, E. J. A Macroscopic and microscopic evaluation of canine and feline skin disease. 1 ed. St. Louis: Mosby-Year Book 1992. 520 p.

9 SCOTT, D. W.; MILLER W. H.; GRIFFIN C. E. Mullerand Kirk's small animal dermatology. 6.ed. Philadelphia: WB. Saunders, 2001, 1528 p.

10 ELDER, D.; ELENITSAS, R. Benign pigmented lesions and malignant melanoma. In: ELDER, D.; ELENITSAS, R.; JAWORSKY, C.; JOHNSON Jr., B. Lever's histopathology of the skin. 8. ed. Philadephia: Lippincott-Raven, 1997. p. 625-684.

11 VAIL, D. M.; MACEWEN, E. G. Spontaneously occurring tumors of companion animals as models for human cancer. Cancer Investigation, v. 18, n. 8, p. 781-792, 2000.

12 COTCHIN, E. Some tumours of dogs and cats of comparative veterinary and human interest. The Veterinary Record, v. 71, n. 45, p. 1040-1054, 1959.

13 OGILVIE, G. K.; MOORE, A. S. A practice manual.
Managing the veterinary cancer patient. New Jersey: Veterinary Learning Systems, 1995. 542 p.

14 BOSTOCK, D.E. Prognosis after surgical excision of canine melanomas. Veterinary Pathology, v. 16, p. 32 40, 1979.

15 SULLIVAN, T. C.; NASISSE, M. P.; DAVIDSON, M. G.; GLOVER, T. L. Photocoagulation of limbal melanoma in dogs and cats: 15 cases (1989-1993). Journal of the American Veterinary Medical Association, v. 208, n. 6, p. 891-893, 1996.

16 YAGER, J. A.; WILCOCK, B. P. Color atlas and text of surgical pathology of the dog and cat. London: Wolfe, 1994. 320 p.

17 BOLON, B.; CALDERWOOD, M. B.; HALL, B. J. Characteristics of canine melanomas and comparison of histology and DNA ploidy to their biologic behavior. Veterinary Pathology, v. 27, p. 96-102, 1990.

18 KRAFT, I. ; FRESE, K. Histological studies on canine pigemented moles. Journal of Comparative Pathology, v. 86, p. 143-155, 1976.

19 ORKIN, M.; SCHWARTZMAN, R. M. Comparative study of canine and human dermatology. Archives of Dermatology, v. 84, p. 227-241, 1961.

20 VAIL, M. D.; WITHROW, S. J. Tumors of the skin and subcutaneous tissues. In: WITHROW, S. J.; MACEWEN, E. G. Small animal clinical oncology. 3 ed. Philadelphia: Saunders, 2001. p. 233- 260.

21 FEENEY, D. A.; HAYDEN, D. W.; WALLACE, L. J. Mammary adenocarcinoma and malignant melanoma metastatic to the lungs of a dog. Journal of the American Animal Hospital Association, v. 16, p. 691-694, 1980.

22 HARVEY, H. J.; MacEWEN, E.G.; BRAUN, D.; PATHAIK, A. K.; WITHROW, S. J. IONGEWARD, S. Prognostic criteria for dogs with melanoma. Journal of the American Veterinary Medical Association, v. 178, n. 6, p. 580-582, 1981.

23 BANKS, W. C.; MORRIS, E. Results of radiation treatment of naturally occurring animal tumors. Journal of the American Veterinary Medical Association, v. 166, n. 11, p. 1063-1064, 1975.

24 BURK, R. L. Radiation therapy in the treatment of oral neoplasia. Veterinary Clinics of North America Small Practice, v. 26, n. 1, p. 155-163, 1996.

25 FRIMBERGER, A. E.; MOORE, A. S.; CINCOTTA, 
L.; COTTER, S. .; FOLEY, J. W. Photodynamic therapy of naturally occurring tumors in animal using a novel bezophenothiazine photosensitizer. Clinical Cancer Research, v. 4, n. 9, p. 2207-2218, 1998.

26 SULAIMON, S. S; KITCHELL, B. E. Canine melanoma: combating a destructive and deadly tumor. Veterinary Medicine, v. 26, n. 12, p. 931-941, 2001.

27 QUINTIN-COLONNA, F.; DEVAUCHELLE, P.; FRADELIZI, D.; MOUROT, B.; FAURE, T.; KOURILSKY, P.; ROTH, C.; MEHTALI, M. Gene therapy of spontaneous canine melanoma and feline fibrosarcoma by intratumoral administration of histoincompatible cells expressing human interleukin2. Gene Therapy, v. 3, n. 12, p. 1104-1112, 1996.

28 ROCHLITZ, C.; JANTSCHEFF, P.; BONGARTZ, G. DIETRICH, P. Y.; QUIQUEREZ, A. L.; SCHATZ, C.; MEHTALI, M.; COURTNEY, M.; TARTOUR, E.; DORVAL, T.; FRIDMAN, W. H.; HERMANN, R. Gene therapy study of cytokine-transfected xenogeneic cells (Vero-interleukin-2) in patients with metastatic solid tumors. Cancer Gene Therapy, v. 6, n. 3, p. 271-281, 1999. 